\title{
Endoscopic ultrasound diagnosis of hydatid membranes in nonobstructive biliary system
}

\author{
Sharad Chandra, Urvashi Chandra, Rajesh Puri ${ }^{1}$ \\ Department of Gastroenterology, Meghraj Memorial Hospital, Jhansi, Uttar Pradesh, 'Department of Gastroenterology, Medicity Hospital, \\ Gurgaon, Haryana, India
}

$\begin{array}{ll}\text { Abstract } & \begin{array}{l}\text { Biliary communication in hepatic hydatid cyst is reported in 1-20\% of patients. These patients } \\ \text { present with fever (70-90\%), right upper quadrant pain }(80 \%) \text {, cholangitis (20-37\%), acute } \\ \text { pancreatitis (rare), liver abscess, and septicemia. Diagnosis of biliary rupture is on abdominal } \\ \text { ultrasound, computerized tomography, and/or magnetic resonance imaging demonstration } \\ \text { of hydatid membranes. We report a case of rupture hydatid cyst where diagnosis was on } \\ \text { endosonographic findings and the patient had normal caliber common bile duct. }\end{array} \\ \text { Key words } & \text { Biliary communication, endoscopic ultrasound, hydatid membranes }\end{array}$

\section{Introduction}

Hepatic hydatidosis with biliary rupture is an unusual but serious complication of echinococcosis. ${ }^{[1]}$ We present a case of biliary communication of hydatid cyst liver where hydatid membranes were documented in common bile duct (CBD) on endoscopic ultrasound (EUS). Interestingly, the patient had nonobstructed biliary system and nonspecific liver function test abnormalities.

\section{Case Report}

A 50-year-old female presented with 3 days history of upper abdominal pain with recurrent vomiting; there was no associated fever or jaundice. In background, there was history of excision of hepatic hydatid cyst with cholecystectomy 11 years back.

Investigation presently showed serum bilirubin $2.02 \mathrm{mg} \%$ with direct $1.12 \mathrm{mg} \%$ and indirect $0.90 \mathrm{mg} \%$, serum

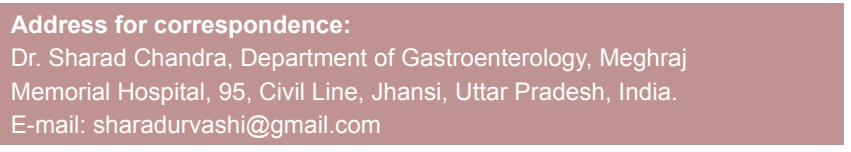

\begin{tabular}{|l|c|}
\hline \multicolumn{2}{|c|}{ Video Available on: www.jdeonline.in } \\
\hline \multicolumn{2}{|c|}{ Access this article online } \\
\hline \multirow{2}{*}{$\begin{array}{l}\text { Website: } \\
\text { www.jdeonline.in }\end{array}$} & Quick Response Code \\
\hline $\begin{array}{l}\text { DOI: } \\
\text { 10.4103/0976-5042.202822 }\end{array}$ \\
\hline
\end{tabular}

glutamic-oxaloacetic transaminase $78.2 \mathrm{IU} / \mathrm{L}(0-32)$ serum glutamic pyruvic transaminase $64.63 \mathrm{IU} / \mathrm{L}(0-33)$, alk $\mathrm{PO}_{4} 106 \mathrm{IU} / \mathrm{L}$ (80-250), serum amylase $37.95 \mathrm{SU} / \mathrm{L}$ $(<50)$, and complete blood count was normal. Ultrasound done showed $68 \mathrm{~mm} \times 48 \mathrm{~mm} \times 39 \mathrm{~mm}$ cystic mass in right lobe of liver with multiple septation, CBD was normal caliber $7.5 \mathrm{~mm}$ (postcholecystectomy), and there was no IHBRD.

The possibility of CBD stone or hydatid biliary rupture was considered. EUS evaluation was done which showed normal caliber CBD with coiled linear echogenic shadows with intervening anechoic area suggestive of membranes [Figure 1 and Supplementary Video 1]. Endoscopic retrograde cholangiopancreatography (ERCP) showed rounded filling defects resembling stones due to coiled membranes in CBD [Figure 2]. Sphincterotomy retrieval of fleshy hydatid membranes [Figure 3] with stent placement was done. No obvious communication with cyst cavity was seen; however, occlusion cholangiogram was not done to avoid the risk of infection in cyst cavity. The patient was started on albendazole her symptoms improved thereafter she was discharged.

This is an open access article distributed under the terms of the Creative Commons Attribution-NonCommercial-ShareAlike 3.0 License, which allows others to remix, tweak, and build upon the work non-commercially, as long as the author is credited and the new creations are licensed under the identical terms.

For reprints contact: reprints@medknow.com

How to cite this article: Chandra S, Chandra U, Puri R. Endoscopic ultrasound diagnosis of hydatid membranes in nonobstructive biliary system. J Dig Endosc 2017;8:44-5. 


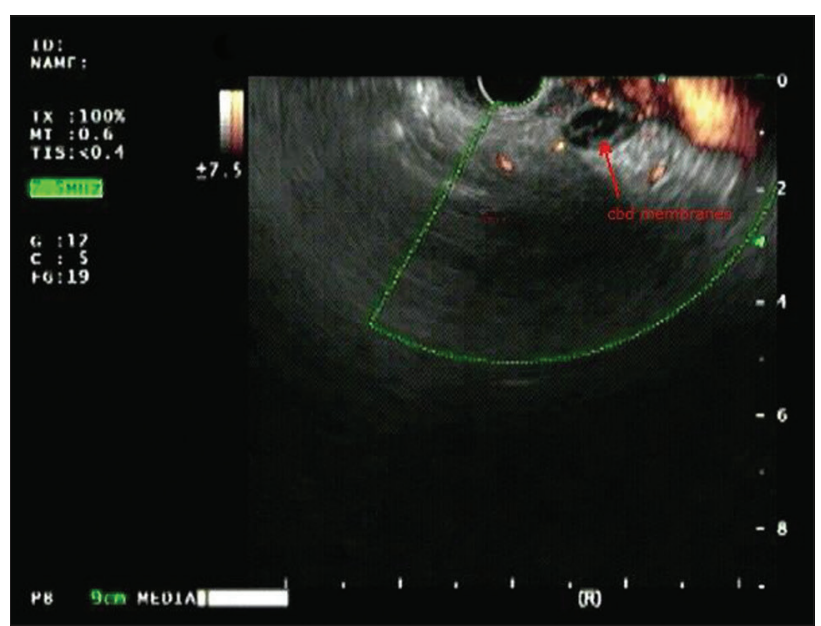

Figure 1: Linear endoscopic ultrasound showing membranes in common bile duct



Figure 2: Endoscopic retrograde cholangiopancreatography cholangiogram showing filling defect in common bile duct

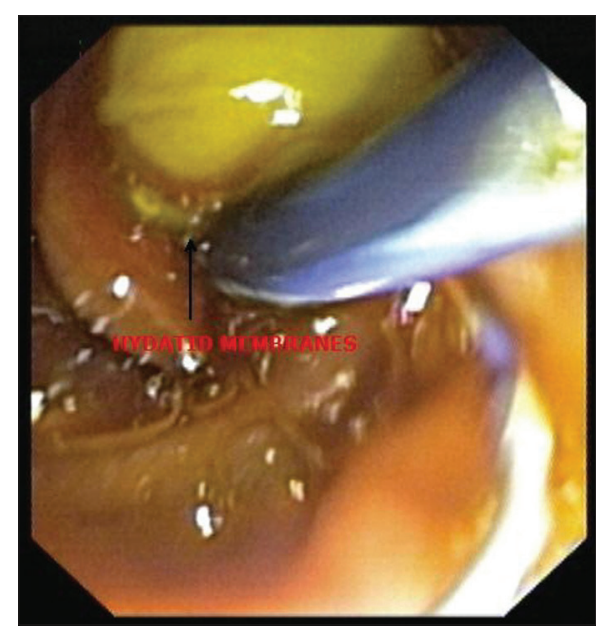

Figure 3: Hydatid membranes extracted from common bile duct

\section{Discussion}

Biliary communication is serious complication of echinococcosis. ${ }^{[1]}$ ERCP with sphincterotomy, membrane clearance, and stent placement has been recommended for managing biliary communication of hepatic hydatid cyst. ${ }^{[2]}$ ERCP is indicated if the patient has obstructed biliary system or is symptomatic with membranes documented in CBD on ultrasound, computed tomography (CT) or magnetic resonance imaging (MRI) ${ }^{[2]}$ EUS when available can demonstrate hydatid membranes. ${ }^{[3-5]}$ Findings reported in bile duct are of echogenic floating membranes, echogenic material with septated appearance or multilayered circular gut wall like image. The present case showed linear echogenic shadows coiled in CBD. In previously reported cases, ${ }^{[3-5]}$ EUS findings of hydatid membranes were reported where biliary system was dilated and there was definitive indication for therapeutic ERCP even on ultrasound. The present case diagnosis and therapy was based on EUS findings which were done to exclude CBD stone or hydatid membranes. EUS possibly scores over CT scan and MRI, especially in nonobstructive system and is available in emergency in patients presenting with cholangitis can be followed by immediate ERCP.

Interestingly patient despite symptoms had nonobstructed biliary system possibly due to intermittent obstruction. Liver functional abnormalities seen were nonspecific, suggesting lower threshold for evaluation for suspected biliary communication in symptomatic patients with large hydatid cyst liver before life-threatening complications such as cholangitis and pancreatitis develops.

\section{Financial support and sponsorship} Nil.

\section{Conflicts of interest}

There are no conflicts of interest.

\section{References}

1. Manouras A, Genetzakis M, Antonakis PT, Lagoudianakis E, Pattas M, Papadima A, et al. Endoscopic management of a relapsing hepatic hydatid cyst with intrabiliary rupture: A case report and review of the literature. Can J Gastroenterol 2007;21:249-53.

2. Simsek H, Ozaslan E, Sayek I, Savas C, Abbasoglu O, Soylu AR, et al. Diagnostic and therapeutic ERCP in hepatic hydatid disease. Gastrointest Endosc 2003;58:384-9.

3. Sharma M, Somasundaram A, Pathak A, Simon EG, Cloa MM. Endoscopic ultrasound in hepatobiliary hydatid disease. Endoscopy 2010;42 Suppl 2:E56-7.

4. Azzolini F, Camellini L, Menozzi G, Sassatelli R. Endoscopic ultrasound image of hydatid membranes in the common bile duct. Dig Liver Dis 2012;44:e19.

5. Rana SS, Bhasin DK, Rao C. Unusual cause of biliary obstruction revealed by endoscopic ultrasound and peroral cholangioscopy. Clin Gastroenterol Hepatol 2013;11:e58. 